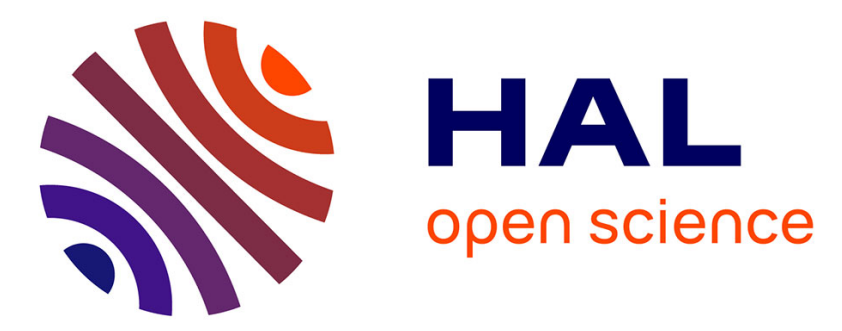

\title{
Oral comfort: A new concept to understand elderly people's expectations in terms of food sensory characteristics
}

Mathilde Vandenberghe-Descamps, Hélène Labouré, Chantal Septier, Gilles Feron, Claire Sulmont-Rossé

\section{To cite this version:}

Mathilde Vandenberghe-Descamps, Hélène Labouré, Chantal Septier, Gilles Feron, Claire SulmontRossé. Oral comfort: A new concept to understand elderly people's expectations in terms of food sensory characteristics. Food Quality and Preference, 2018, 70, pp.57-67. 10.1016/j.foodqual.2017.08.009 . hal-02142357

\section{HAL Id: hal-02142357 \\ https://institut-agro-dijon.hal.science/hal-02142357}

Submitted on 18 Feb 2021

HAL is a multi-disciplinary open access archive for the deposit and dissemination of scientific research documents, whether they are published or not. The documents may come from teaching and research institutions in France or abroad, or from public or private research centers.
L'archive ouverte pluridisciplinaire HAL, est destinée au dépôt et à la diffusion de documents scientifiques de niveau recherche, publiés ou non, émanant des établissements d'enseignement et de recherche français ou étrangers, des laboratoires publics ou privés. 


\title{
Oral comfort: a new concept to understand elderly people's expectations in terms of food sensory characteristics
}

Authors: Mathilde Vandenberghe-Descamps ${ }^{\mathrm{a}}$, Hélène Labouré ${ }^{\mathrm{a}}$, Chantal Septier ${ }^{\mathrm{a}}$, Gilles Feron $^{\mathrm{a}}$, Claire Sulmont-Rossé

${ }^{a}$ Centre des Sciences du Goût et de l'Alimentation, AgroSup Dijon, CNRS, INRA, Univ. Bourgogne Franche-Comté, F-21000 Dijon, France.

Short manuscript title: Food comfortability in elderly people

\begin{abstract}
:
In the elderly population, ageing frequently impact on the different aspects of oral physiology that play a key role in eating behavior. In the context of an aging population, it is crucial to develop a food supply tailored for the elderly people in order to prevent the onset of malnutrition. To meet this challenge, we looked for the concept of "oral comfort" when eating a food. The present study aimed at i) exploring the concept of oral comfort when eating according to elderly people in order to develop a questionnaire to evaluate the oral comfort when eating a food and ii) asking elderly people to evaluate various meat and cereal products using this questionnaire. Results of focus groups highlighted that oral comfort when eating a food is a multi-dimensional concept which includes dimensions related to food oral processing (ability to form and swallow food bolus), food sensory properties (texture and taste) and to a lesser extent pain sensations. Furthermore, the oral comfort questionnaire developed in the present study enabled a discrimination of products and highlighted the fact that some products supposed to fit with elderly people capacities and needs where not rated as the most comfortable foods by the elderly people. The concept of oral comfort when eating a food should be taken into account by those who are willing to design food products tailored to the elderly population.
\end{abstract}


The questionnaire could be an interesting tool to assess oral comfort when eating a food in the elderly population.

Keywords: aging, older adults, oral comfort, texture, food bolus, oral health

\section{Highlights}

- A definition of oral comfort when eating a food in an elderly population is proposed

- The understanding of oral comfort allowed the development of a tool suitable for elderly people to evaluate the oral comfort when eating a food: the oral comfort questionnaire

- The assessment of oral comfort in a selection of cereal-based and meat-based products enabled a discrimination between products

- The concept of oral comfort when eating a food should be taken into account by those who are willing to design food products tailored for the elderly population.

\section{INTRODUCTION}

In the elderly population, the cumulative effects of physiological ageing, diseases and drugs frequently impact on the different aspects of oral physiology that play a key role in eating behavior (for a review, see Mioche, Bourdiol, \& Peyron, 2004). First, ageing often goes along with a reduced strength in jaw muscles (Fontijn-Tekamp, van der Bilt, Abbink, \& Bosman, 2004) or with tooth loss (Ikebe et al., 2012), which in turn alter masticatory ability (Mioche, Bourdiol, Monier, \& Martin, 2002). According to Steele, Ayatollahi, Walls, \& Murray (1997), the conservation of at least 21 well distributed teeth is necessary to maintain a good masticatory function (see also Kohyama, Mioche, \& Bourdiol, 2003). Wearing prosthesis may restore the masticatory function, which remains, however, less efficient compared to natural dentition (Fucile, Wright, Chan, Yee, Langlais, \& Gisel, 1998; Veyrune and Mioche, 2000; Bessadet, Nicolas, Sochat, Hennequin, \& Veyrune, 2013). Second, ageing may often be accompanied by 
a decrease in salivary flow (Vandenberghe-Descamps et al., 2016) or changes in salivary composition (Vissink, Spijkervet, \& Amerongen, 1996). As the first digestive fluid in contact with food, saliva is a key factor assisting the oral processing of food, whereby food is transformed into a bolus to be swallowed. During the mastication process, the lubrication function of saliva allows moistening of food and supports the creation of a bolus (Prinz, \& Lucas, 1997). Furthermore, some food components are released from the food matrix and dissolved in saliva, where they can be influenced by the presence of salivary components such as salivary enzymes that begin the process of food digestion (i.e. alpha-amylase) or metabolize flavor compounds (i.e., esterases, glycosidases) (Buettner, 2002a; 2002b). Consequently, a decrease in salivary flow or change in saliva composition may have an impact on texture and taste perception (Engelen et al., 2007; Neyraud, 2014). Third, swallowing disorders such as inaccurate initial insertion and foodstuff control, drooling and rapid movements of the tongue as well as delayed swallowing response may also appear with age (Ekberg, \& Feinberg, 1991; Britton, 2016). According to Ney, Weiss, Kind, \& Robbins (2009), presbyphagia corresponds to a moderate impairment of swallowing function induced by a decrease in mastication and salivation efficiency which in turn compromise the formation of a food bolus easy to swallow. Severe swallowing disorder is referred to dysphagia, which may result from an aggravation of presbyphagia (Ney et al., 2009) or from a stroke or a neurological disease (Britton, 2016). Dysphagia increases the risk for foods or liquids entering the airway, and thus the risk for pulmonary complications (Marik, \& Kaplan, 2003) or even choking and mortality (Sharma, Fletcher, Vassallo, \& Ross, 2001). Finally, elderly people may suffer from dry mouth or xerostomia, gum disease, mycosis which may induce uneasiness or even pain during food consumption. These oral sensorial complaints often results from drug intake and polypharmacy (Nagler, \& Hershkovich, 2005). For instance, Sreebny, \& Schwartz (1997) reported 42 
xerogenic drugs categories among which some are frequently prescribed to the elderly (e.g., antihypertensives, anti-arrhytmic medications, psychotropics agents).

Several studies have demonstrated a negative impact of oral disorders on food intake. In particular, a negative relationship between masticatory ability and/or dental status (e.g. number of teeth, number of occlusal contact, denture fitting) on the intake of fruits and vegetable (see Tada, \& Miura, 2014, for a review), meat (Savoca et al., 2010; Marcenes, Steele, Sheiham, \& Walls, 2003), fish (Kim et al., 2007) and nuts (Marcenes et al., 2003; Kimura et al., 2013) was observed. For instance, in Kimura et al. (2013), low chewing abilities evaluated by colorchangeable gum was associated with lower intake of vegetables, beans and nuts. Savoca et al. (2010) observed lower fruit, meat and beans intake in older adults with severe tooth loss (0-10 teeth remaining) compared to those with $11+$ teeth after adjusting for age, gender, ethnicity, economic status and dental insurance. Only a few studies considered the impact of salivation on food intake (see Muñoz-González et al. (in press) for a review). Actually, Iwasaki et al. (2016) observed lower vegetable and fish intake in older adults with low salivary flow $(<0.5$ $\mathrm{mL} / \mathrm{min}$ ) compared to those with high salivary flow. Obviously, these changes in food intake go along with changes in nutrient intake (Van Lancker et al., 2012; Tada, \& Miura, 2014), which in turn can induce weight loss, sarcopenia, and even malnutrition (Keller, 1993; Chen, Schilling, \& Lyder, 2001).

While the impact of oral health on food intake in the elderly has been largely reported in the literature, the impact of oral health on the difficulties encountered by the elderly when eating is less explored. Furthermore, most of the few studies that have explored eating difficulties in the elderly have targeted only one dimension, usually chewing difficulties (e.g., Hsu, Lee, Wu, Lan, Huang, \& Yen, 2014; Fontijn-Tekamp et al., 2000; Takata et al., 2008). Some have targeted two dimensions (e.g., chewing difficulties and pain sensations in Brennan, Spencer, \& RobertsThomson, 2008), but to the best of our knowledge, none have targeted all the difficulties liable 
to be encountered by the elderly when eating a food. Moreover, former studies used either a general question (e.g., "Have you found it uncomfortable to eat any foods because of problems with your teeth or mouth?" Silva, Demarco, \& Feldens, 2015) or a question related to a specific food category (e.g., "boiled vegetables" or "firm foods such as steak or dried apricots" in Brennan et al., 2008), but to the best of our knowledge, none asked questions during the actual consumption of a food. However, it is worth to explore more in detail which difficulties are encountered by the elderly in a eating situation, both to better understand the impact of oral health on food intake (namely, to better understand which difficulties lead an older individual to avoid one food or another), and consequently to develop a food supply tailored to the oral capacities of the elderly people. To meet this challenge, we looked for the concept of "oral comfort" when eating a food. By "oral comfort", we mean the "oral sensations" experienced by the elderly people when eating a food, which may range from a negative side (e.g. discomfort, pain) to a positive side (e.g. easiness, pleasure). In the elderly population, it could be hypothesized that these oral sensations influence food choices as well as eating pleasure, appetite and willingness to eat, which in turn may impact dietary variety and food intake. Consequently, oral comfort might be an essential concept to evaluate the acceptability of food products by an elderly population, and thus a key concept to develop foods for the elderly people that meet their oral capacities, namely foods that are associated with positive oral sensations such as easiness to eat and eating pleasure.

In the literature, Witter, De Haan, Käyser, and Van Rossum (1994) associated "oral comfort" with the absence of pain in the mouth, satisfaction toward masticatory ability and aesthetic, and for denture wearers, the absence of complaints regarding their denture. However, this definition of "oral comfort" is more related to "dental comfort" than to the "oral sensations" perceived when eating a food. In food area, some authors outlined the concept of "comfort food", which refers to palatable foods that are consumed to meet physiological needs (i.e., some foods can 
have addictive qualities) or psychological needs related to factors such as social context or social identification (Wansink, Cheney, \& Chan, 2003; de Castro \& de Castro, 1989). Again, this concept of "comfort food" does also not relate to the perceived oral comfort during food consumption.

Consequently, the aim of the present study was to explore the concept of "oral comfort" when eating a food in the elderly population. A first step consisted in running focus groups with elderly people in order to develop a questionnaire to evaluate the oral comfort when eating a food (qualitative phase). A second step consisted in asking elderly people to evaluate various meat and cereal products using this questionnaire (quantitative phase). Expected results of these studies were i) to set up a definition of "oral comfort" when eating a food in the elderly population, ii) to propose a validated tool, suitable for elderly people, to evaluate the oral comfort when eating a food, and iii) to assess whether the "oral comfort" concept can differentiate food products.

\section{DEVELOPPING A QUESTIONNAIRE THROUGH FOCUS GROUP TO ASSESS ORAL COMFORT WHEN EATING A FOOD (QUALITATIVE PHASE)}

\section{1) Focus groups}

\section{Materials and methods}

Three focus groups were organized with 6 elderly people each (13 women, 5 men, mean age $=$ $79.6 \pm 5.0$ ). Two focus groups were performed at our laboratory with independently living volunteers, and one was performed in a retirement home with frailer elderly people. The recruitment criteria were the following: older than 65 years old, no acute pathological episodes at the time of the experiment, no cognitive disorder and able to express themselves. To check these last criteria, participants completed the Mini Mental State Examination (MMSE). Only 
participants scoring at least 24 out of 30 , meaning normal cognition, were included in the study (Folstein, Folstein, \& Mchugh, 1975).

For the two focus groups performed with independently living volunteers, we managed to have volunteers ranging from a poor to a good oral health in each group, based on the number of functional units (i.e. a pair of posterior antagonist teeth that had at least one contact area during chewing.) and salivary flow rates (Leake, Hawkins, \& Locker, 1994; Gupta, Epstein, \& Sroussi, 2006). For a first group $(n=6)$, the number of functional units varied from 2 to 9 and the salivary flow rates varied from $0.076 \mathrm{ml} / \mathrm{min}$ to $0.697 \mathrm{ml} / \mathrm{min}$ and $0.285 \mathrm{ml} / \mathrm{min}$ to $4.012 \mathrm{ml} / \mathrm{min}$ for the resting and stimulated salivary flows respectively. For a second group $(n=6)$, the number of functional units varied from 2 to 8 and the salivary flow rates varied from $0.049 \mathrm{ml} / \mathrm{min}$ to 0.631 $\mathrm{ml} / \mathrm{min}$ and $0.295 \mathrm{ml} / \mathrm{min}$ to $2.182 \mathrm{ml} / \mathrm{min}$ for the resting and stimulated salivary flows respectively. In parallel, the ability to swallow was tested through the three following tests: measure of tongue pressure, ability to form a food bolus ready to be swallowed safely and glatzel mirror test to detect velopharyngeal insufficiency (Chow et al., 2015). Based on the tests' results, none of the volunteers presented swallowing disorders. Unfortunately, it was not possible to carry out dental exams and salivary flow measurements for the volunteers living in nursing home, but it was checked with the nurses that none of the volunteers presented swallowing disorders.

During the focus groups, the moderator directed the flow of the discussion and ensured that all of the important issues were discussed. Before starting the discussion a short introduction about the subject of the focus group was given by the moderator and a self-introduction of the participants took place.

Each focus group consisted in three parts: 
a) Brainstorming about oral comfort. The participants were asked the question "what comes to your mind when I say "oral comfort"?" and were invited to tell out loud the first words that popped-up to their minds. Every word that was cited was written on a paper-board in order to make the words visible to everyone.

b) Personal experience on most comfortable and most uncomfortable food. The volunteers were asked to express what were the most uncomfortable food and the most comfortable food for them, and describe what makes the food uncomfortable or comfortable during its consumption.

c) Tasting phase. Participants were served with 8 delicatessen and salads (starter course), 8 meat and veggie dishes (main course), 8 cheeses and breads (cheese course) and 8 sweet products (dessert course) (Table 1). For each course, they were asked to choose one uncomfortable and one comfortable food among the eight proposals, to taste it, to confirm or not their choice and to describe what makes the food uncomfortable or comfortable during its consumption.

\section{Table 1 about here}

The sessions lasted between 60 and $80 \mathrm{~min}$. The three focus groups were videotaped and voicerecorded. A transcription of the focus groups was performed based on those tools. The analyses were performed in four stages:

a) Lemmatization: reduction of words to their root forms. This stage consisted in grouping together words with the same semantic origin. In most of the cases we grouped together masculine, feminine, singular and plural forms of adjectives;

b) Analysis of occurrence frequencies. This analysis consisted in determining which words were the most frequently cited by the participants throughout all the focus groups; 
c) Semantic analysis. This analysis consisted in regrouping together the words that refer to the same dimension of the act of eating.

\section{Results of the focus groups}

During the brainstorming, 84 verbatims were cited comprising 46 different words. During the second step of the focus group, which consisted in telling a personal experience what is the most comfortable and the most unconfortable food, generated 93 words comprising 43 different words. The final step of the focus group - the tasting session - generated 686 words comprising 109 different verbatims. On the whole, the volunteers cited 139 different words related to oral comfort with a number of citations varying from 1 to 63 throughout all the focus groups. The ten most cited words are: taste (cited 63 times), to masticate (cited 49 times), to swallow (cited 43 times), to chew (cited 43 times), cooked (cited 39 times), to eat (cited 33 times), hard (cited 29 times), dry (cited 29 times), tender (cited 24 times) and melting (cited 20 times).

\section{2) Development of a questionnaire}

\section{Selection of dimensions, items and scales}

The authors of the present paper developed a questionnaire that aims at evaluating the oral comfort of different food for an elderly population, based on the analysis of the verbatim collected during the focus group.

A semantic analysis was carried out to select the dimensions to be included in the questionnaire. This analysis consisted in sorting together the words that refer to the same semantic dimension. This analysis highlighted 11 categories of words: mouth anatomy (i.e. taste papillae), bolus formation (i.e. to masticate), oral pain sensations (i.e. burning sensation), cooking (i.e. to grate), eating (i.e. to enjoy eating), body sensations (i.e. appetizing), meal environment (i.e. atmosphere), taste perception (i.e. sweet), odor (i.e. odor), texture perception (i.e. hard) and 
visual (i.e. aspect) (Table 2).Three categories (bolus formation, texture and taste perception) stand out from the others due to their important number of words and number of citations during the focus groups. As those categories of words were found to be largely represented, they were considered as essential to define the concept of oral comfort and were kept in the questionnaire. A fourth category was kept in the questionnaire as well: oral pain sensations. This category was poorly cited as it was only cited during the focus group organized in the retirement home and therefore concerns few elderly people. However, we hypothesized that when pain sensations occur during food consumption, oral comfort can be highly impacted. Indeed, during the focus group in the retirement home, one volunteer had the following reaction: "I have irritation problems, therefore [vinegar] burns me, I can't stand having it on my tongue".

Once the dimensions were chosen, we selected the most frequently cited words for each dimension. Accordingly, we selected 6 items for bolus formation (occurrence frequency ranged from $19.0 \%$ for masticating to $3.1 \%$ for humidification with saliva), 8 items for texture (occurrence frequency ranged from $8.7 \%$ for hard to $1.5 \%$ for sticky) and 5 items for taste (occurrence frequency ranged from $11.2 \%$ for sugary to $1.2 \%$ for bitter). For pain dimension, only the item "burning or spicy sensation" was mentioned during the focus group (occurrence frequency: 18\%). Four additional items were chosen by asking a dentist of potential painful sensations that could occur when eating a food. Finally, a general question on food comfort was also added to the questionnaire.

All the items of a given dimension were associated to the same scale. Scales were chosen to be consistent with the related question and to avoid any understanding ambiguity. The length of the scales varied depending on the dimensions (5-point for the general question; 6-point for bolus formation; 4-points for mouth pain, texture and taste). For the general question on food comfortability, we used the structure of the hedonic scale developed by Maître, Symoneaux, and Sulmont-Rossé (2014) for elderly people (i.e., a discrete scale including an odd number of 
5 points, each point being associated with a label). We added the label "impossible" in the scales for the bolus formation items as some elderly people reported being incapable of biting and chewing some foods during focus groups. For mouth pain, texture and taste items, we selected a very simple intensity scale as recommended by Maître et al. (2014).

\section{Presentation of the questionnaire}

The questionnaire includes five sections (Figure 1):

- A first general question on food comfort that the participants answered using a 5-point scale from "Very uncomfortable" to "Very comfortable."

- A second section on bolus formation included five items: the ability to cut the food with incisors, the ability to cut the food with premolars, the ability to masticate the food, the ability to humidify the food with saliva, and the ability to swallow the food. For each item, participants answered on 6-point scale from "Impossible" to "Very easy." This section also included an item on the time needed to form the food bolus; participants answered using a 6-point scale from "Impossible" to "Very brief."

- A third section on pain perception included five items: burning or spicy sensation, muscular pain, articular pain, dental pain and gum pain. For each item, participants answered on a 4-point scale from "Extremely" to "Not at all."

- A fourth section on texture perception included eight items that were evaluated on their intensity: sticky, stringy, greasy, dry, doughy, melting, firm and hard. The items were rated on a 4-point scale from "Extremely" to "Not at all."

- A fifth section on taste perception included five items: taste intensity and the saltiness, sweetness, sour and bitter perceptions. For each item, participants answered on a 4-point scale from "Extremely" to "Not at all."

\section{Figure 1 about here}




\section{3) Validation of the questionnaire}

The first version of the questionnaire was sent to 40 elderly people (older than 65 years old, independently living, 19 women and 21 men) in order to evaluate the feasibility of the questionnaire. The surveyed population received the questionnaire by post-mail and was asked to complete the questionnaire at home by eating a food to choose among a short list: a piece of Comté cheese (semi-hard cheese made of unpasteurized cow's milk), a cooked chicken escalope or a madeleine (small cake cooked in a mold, made of flour, sugar, egg and butter). An evaluation sheet was added to the questionnaire in order to collect background information regarding the completion of the questionnaire. Thus, the time needed to complete the questionnaire and its evaluation (very long, long, moderate, short or very short), the easiness to answer the questions and any difficulty encountered during the completion were collected.

Of the 40 questionnaires sent, 31 were completed by the elderly people (14 women and 17 men) and sent back to the experimenter. The mean time of completion according to the elderly people was of 10 minutes which was considered as short or very short for all the respondents. Twentysix respondents declared that they did not encounter any problem for completing the questionnaire, 4 declared that they encountered little problem and 1 respondent did not give his appreciation. The problems encountered while completing the questionnaire were the difficulty to differentiate firm to hard (texture descriptors) and bitter to sour (taste descriptors). Therefore, a decision was made to clarify those points at the beginning of each session using examples of common food such as Comté cheese vs crispbread or lemon vs grapefruit for the future utilization of the questionnaire.

\section{USING THE QUESTIONNAIRE TO ASSESS FOOD COMFORTABILITY (QUANTITATIVE PHASE)}

\section{1) Materials and methods}




\section{Participants}

A meat panel and a cereal panel were recruited for the tasting sessions. In the meat panel, 39 volunteers ( 21 women and 18 men) aged between 65 and 87 years old $(M=72.64 \pm 1.0)$ were included whereas in the cereal panel 42 volunteers ( 21 women and 21 men) aged between 65 and 87 years old $(M=73.57 \pm 0.9)$ were included. The recruitment criteria were the following: older than 65 years old, no acute pathological episodes at the time of the experiment, scoring at least 24 on the mini mental state evaluation (MMSE) (Folstein et al., 1975). In each group, we managed to have volunteers ranging from a poor to a good oral health, based on the number of functional units (i.e. a pair of posterior antagonist teeth that had at least one contact area during chewing) and salivary flows (Leake et al., 1994; Gupta et al., 2006). Overall the 81 volunteers, the number of functional units varied from 0 to $10(\mathrm{M}=5.57$; SEM=0.019) and the resting salivary flow rate varied from $0.049 \mathrm{ml} / \mathrm{min}$ to $0.78 \mathrm{ml} / \mathrm{min}(\mathrm{M}=0.21 ; \mathrm{SEM}=0.005)$.

\section{Products}

Six meat-based products and six cereal-based products were chosen in order to have contrasted textures. The meat-based products included beef cheek, plain beef, ground beef, chicken meatballs, chicken aiguillette and ground chicken reconstituted in an aiguillette shape (Table 3). They were all provided by Terrena Innovation ${ }^{\circledR}$. They were cooked just before serving according to the recipes provided by the supplier: beef cheek was received already cooked and needed a reheating in a water bath; the plain beef and ground beef were cooked in a frying pan at high temperature during 6 minutes ( 3 minutes for each side); the chicken meatballs, the chicken aiguillette and the ground chicken reconstituted were reheated in a micro-wave at 800 Watt during 5 minutes as recommended by the supplier. The products were served when the temperature in the heart of the product reached at least $+65^{\circ} \mathrm{C}$. The cereal-based products included a crispbread (Heudebert $\left.{ }^{\circledR}\right)$, a financier (Cerelab $\left.{ }^{\circledR}\right)$, a madeleine (Saint-Michel $\left.{ }^{\circledR}\right)$, a 
sponge cake $\left(\right.$ Cerelab $\left.{ }^{\circledR}\right)$, a milk roll (Pasquier $\left.{ }^{\circledR}\right)$ and a protein enriched milk roll (Cerelab $\left.{ }^{\circledR}\right)$ (Table 3). They were served at room temperature $\left(20.5 \pm 0.5^{\circ} \mathrm{C}\right)$. For both product categories, the served quantity of each product was calculated to be sufficient for answering the entire questionnaire (Table 3).

\section{Table 3 about here}

\section{Procedure}

The volunteers were invited to take part in one session where they had to taste 6 products, either the meat-based products or the cereal-based products. For each product, the volunteers were asked to answer the "food comfortability" questionnaire (Figure 1). At the beginning of each session, the questionnaire was presented to the volunteers by the experimenter, with specific examples for defining the terms firm, hard, bitter and sour. No specific training was performed before the sessions. During the sessions, the volunteers were free to bite the products as many times as they wanted in order to answer the questions on the "food comfortability" questionnaire. The participants were given a 3-min rest time between samples, and they were free to drink as much water as they needed during the session. The sessions were conducted in a sensory room equipped with individual booths according to the AFNOR standard (AFNOR, 1987) and under white light. The room temperature was $20.5 \pm 0.5^{\circ} \mathrm{C}$. The products were presented in an order determined by a William Latin square design; they were coded with a three digit number.

In order to check the questionnaire repeatability, participants from the cereal panel were invited to come back to the laboratory three months later for a second session. Thirty-eight volunteers out of the 42 who completed the first cereal session came back for the second cereal session (20 women, 18 men, mean age $m=73.7 \pm 6.2$ ). During this session, they were asked to rate the same cereal products using the same "food comfortability" questionnaire, under similar experimental 
conditions. The test retest was not carried out on meat-based products because the supplier was not able to provide us with two batches (one for each replication) made of the same lot of meat and could not guarantee texture homogeneity between two batches produced with different lots of meat.

\section{Data analysis}

Participants' ratings were transformed on scores varying from 0 to 100 to facilitate further reading. Separate analyses were conducted for the meat products and for the cereal products. For each item of the "food comfortability" questionnaire, scores were submitted to an Analysis of Variance (ANOVA) with one fixed factor (product) and one random factor (participant). Post-hoc comparisons were performed using the Student Newman Keuls test. Means (M) were associated with their standard errors (SEM). The threshold for significance was set at $5 \%$. Statistical analyses were conducted using R-studio software version 3.3.1 with the "nlme" package for linear mixed models and the "agricolae" package for post-hoc analyses (R Development Core Team, 2006). The significant attributes $(\mathrm{p}=0.05)$ for the product effect were arranged in a FLASH table (Schlich, 1998; orcherot \& Schlich, 2000). The results of the repeated session of cereal-based products were compared to the results of the first cereal-based session. The data of both sessions were submitted to an ANOVA with two fixed factors, namely product and session, and one random factor (participant).

\section{2) Results}

\section{Results on meat-based products}

The results on the general question on food comfortability show that there is a difference of oral comfort perception between the products $(F(5,33)=7.29 ; \mathrm{P}<0.001)$. Indeed, the aiguillette, the beef cheek and the chicken balls are the most comfortable products while the plain beef is the most uncomfortable food. 
The FLASH table presented in Table 4 highlights the differences between the meat-based products perceived by the volunteers. The ground and plain beef are the products perceived as less comfortable. For those two products, the food bolus is more difficult to form than for the other products. Eating the plain beef generates some slightly higher rates on pain sensations on the oral cavity. Both the ground and the plain beef are characterized by a harder and less melting texture that the comfortable products.

The chicken balls, the aiguillette and the beef cheek are comfortable products. The food bolus is easy to form in mouth. Those three products have a low score on the hardness attribute.

It is interesting to notice that the reconstituted aiguillette and the ground beef, judged as less comfortable than the beef cheek, are characterized by a dry, doughy and little melting texture as well as a little intense taste. On the contrary, the beef cheek is characterized by a stringy texture but not dry nor doughy and melting. Its taste is more intense than the one of the reconstituted aiguillette or ground beef.

\section{Table 4 about here}

\section{Results on cereal-based products}

The results on the general question on food comfortability show that there is a difference of oral comfort perception between the products $(F(5,36)=5.95 ; \mathrm{P}<0.001)$. The sponge cake is the most comfortable food according to the student test while the crispbread and the enriched milk roll are the most uncomfortable foods.

The FLASH table presented in Table 5 highlights the differences between the cereal-based products perceived by the volunteers. The crispbread and the protein enriched milk roll are the two products judged as less comfortable. For both of them, the food bolus is more difficult to form than for the other products. The crispbread is characterized by a hard, firm, dry and a little 
melting texture. Its taste is little intense. The protein enriched milk roll is characterized by a firm, dry, doughy and little melting texture. The two products are judged more salty than the other matrices. Finally, eating the crispbread provokes slightly gum and dental pain sensations while eating the protein enriched milk roll provokes a slightly burning sensation.

The Madeleine and the sponge cake are judged as comfortable products. The food bolus is easy to form in mouth. Those products have a texture that is not hard nor firm, but melting. The madeleine has a doughy, greasy but not dry texture. The two products are judged as little salty.

Finally, the Financier and the milk roll are considered as moderately comfortable. The financier, as for the madeleine, has a doughy, greasy but not dry texture. Regarding the milk roll, compared to the protein enriched milk roll, it has a less firm, less dry and more melting texture.

\section{Table 5 about here}

\section{Results on the repeated session of cereal-based products}

The results of the repeated session showed a significant session effect for five descriptors: ability to masticate the food $(\mathrm{t}(1)=12.22 ; \mathrm{P}<0.001)$, ability to swallow the food $(\mathrm{t}(1)=4.69$; $\mathrm{P}=0.03)$, stringy $(\mathrm{t}(1)=9.92 ; \mathrm{P}=0.002)$, greasy $(\mathrm{t}(1)=4.75 ; \mathrm{P}=0.03)$ and doughy $(\mathrm{t}(1)=6.51$; $\mathrm{P}=0.01$ ). Participants perceived the products as easier to masticate and swallow and they rated them as stringier and greasier during the second session than during the first session. A significant product $\times$ session interaction was observed for only the descriptor doughy: the financier belongs to the 'doughy' products in the first session (with the madeleine, the milk roll and the protein-enriched milk roll) while it belongs to the "not doughy" products in the second session (with the crispbread) $(\mathrm{t}(3)=3,25 ; \mathrm{P}=0.02)$. None of the other questionnaire items was associated with a significant product $\times$ session interaction providing that participants were quite repeatable when scoring the cereal-based products for food comfortability. 


\section{DISCUSSION}

As a reminder, expected results of these studies were i) to set up a definition of "oral comfort" when eating a food in the elderly population, ii) to propose a validated tool, suitable for elderly people, to evaluate the oral comfort when eating a food, and iii) to assess whether the "oral comfort" concept can differentiate food products. In the following discussion, we will consider each point and end by the limits and perspectives of our study.

\section{Oral comfort: a multidimensional concept}

Results of focus groups highlight that oral comfort when eating a food is a multi-dimensional concept which includes dimensions related to food oral processing (ability to form and swallow food bolus), food sensory properties (texture and taste) and to a lesser extent pain sensations. Results of the quantitative phase show that the less comfortable foods (plain beef, ground beef, crispbread, protein enriched milk roll) were systematically rated as more difficult to chew, to humidify and to swallow as well as firmer and/or harder than the most comfortable foods (chicken balls, chicken aiguillette, beef cheek, madeleine, sponge cake). Despite average means were quite low, the least comfortable food in the meat study (plain beef) induced more pain sensations than the other products. Beyond these first dimensions (food oral processing, pain and hardness), ratings also revealed additional sensory properties or combinations of sensory properties that may contribute to oral comfort. Thus, foods which were perceived as dry and little melting also tend to be less comfortable than foods which were perceived as melting and little dry (ground beef, reconstituted chicken aiguillette versus beef cheek; crispbread, protein enriched milk roll versus financier, madeleine). In the same way, taste intensity and saltiness (for meat products) or sweetness (for cereal product) tended to be rated lower in uncomfortable food than in comfortable food (ground beef versus beef cheek, chicken aiguillette and chicken balls; crispbread versus madeleine and financier), but this was not true for plain beef. However, 
it can be assumed that these dimensions (dryness, melting, taste intensity) play a secondary role in the definition of oral comfort. In fact, plain beef was rated as uncomfortable despite scoring lower on dryness and higher on taste intensity.

To sum up results from the qualitative and quantitative phases, the concept of "oral comfort" from the elderly perspective may be defined as the following: When eating, oral comfort mainly depends on easiness to chew, to humidify and to swallow as well as on texture softness. Oral pain sensations that occur when eating decrease oral comfort. Beyond these first dimensions, oral comfort also tends to be lower for dry and little melting textures, as well as for low taste intensity foods.

\section{Development of a questionnaire to assess oral comfort}

The "oral comfort" questionnaire developed in the present study proved to be easy to fill-up and repeatable. In fact, neither volunteers from the validation step (qualitative phase) nor volunteers from the quantitative phase have reported problems when filling the questionnaire. Furthermore, the questionnaire was rated as easy to understand. Developing sensory and consumer science methods specifically adapted to older adults is of crucial importance when considering this specific population (Methven, Jiménez-Pranteda, \& Lawlor, 2016). Indeed, our questionnaire was developed for and with elderly people: items and scales were chosen from the verbatim collected during the focus groups carried out with elderly people. Furthermore, the test re-test of the questionnaire carried out on the cereal products with three-month inbetween revealed only one product $\times$ session interaction over 25 items, the interaction was observed for the doughy scale.

\section{Oral comfort: a "tool" to characterize food products}


On the whole, the elderly volunteers rated the food products as rather comfortable: the averages scores ranges from 54 for the plain beef to 85 over 100 for the sponge cake. However, volunteers discriminated the products with the oral comfort scale for both the meat-based and cereal-based products. Regarding the others items, they discriminated the products on 20 over 24 items for the meat products and on 22 over 24 items for the cereal products. Among others, the use of the present questionnaire highlighted some interesting results regarding two products supposed to fit with elderly people capacities and needs, namely the ground beef and the protein enriched milk roll.

In fact, some French nutritional guidelines recommend ground beef for elderly people suffering from chewing difficulties (e.g., French Contract Catering Industry and Nutrition Study Group, 2015; French National Nutritional and Health Program, 2015). However, and contrary to what as expected, ground beef was rated as one of the less comfortable products among the five meat products that were assessed in the present study, with a score of 61 over 100 on the oral comfort scale. Participants rated this product as hard and difficult to chew, as well as dry and difficult to humidify. In parallel, the protein enriched milk roll was designed to improve the nutritional intake of malnourished elderly people. Again, this product was rated as one of the less comfortable products among the five cereal products ( 70 over 100 on the oral comfort scale). This product was perceived as difficult to humidify and swallow as well as dry, doughy and firm. The cooking mode or tasting conditions could be one of the reasons why the volunteers rated the products as less comfortable than the other products. Regarding the ground beef, it was prepared according to the good hygiene practice guidelines in mass catering. Therefore, the meat was well cooked and was held on a water-bath few minutes before serving, which could have led to a drying of the meat. Regarding the protein enriched milk roll, the volunteers did not have the opportunity to soak it in milk, tea or coffee during the tasting session, while some volunteer can usually use those practices at home. Therefore, the protein enriched milk 
roll might have been rated as drier and less comfortable than if the conditions were different. However, the used conditions in the present study can be close to the ones observed in retirement homes or institutions. Therefore, and beyond nutritional requirements, it could be worth taking into account oral comfort when providing recommendations and/or developing food products tailored to oral capacities or nutritional needs of the elderly people, in order to ensure a good food acceptability.

\section{Limits and perspectives of the present study}

The present study allowed defining the concept of "oral comfort" and developing a repeatable and discriminative questionnaire to assess this concept when eating a food in the elderly population. Knowing the oral health of the volunteers, another work will be held to better understand the impact of oral health of the elderly (masticatory efficiency, salivary flow, swallowing efficiency) on the perception of "oral comfort" when eating a food. Further work is also needed to better understand the impact of "oral comfort" on eating pleasure and food intake. In fact, we can hypothesize that the cumulative effect of ageing and pathologies can induce oral disorders, which in turn might alter oral comfort perception. This decline in "oral comfort" might have a negative impact on food choice as well as eating pleasure, appetite and willingness to eat, which in turn may impact dietary variety and food intake. (Figure 2). However, further work is needed to infirm or confirm this pathway. At the moment, a preliminary study on the impact of dental status (i.e., the number of occlusal contact) and salivary flow on "oral comfort" perception when eating a food showed only little relationships. However, conclusions of the paper need to be reinforced on a larger number of subjects (Vandenberghe-Descamps, Sulmont-Rossé, Septier, Feron, \& Laboure, Submitted).

\section{Figure 2 about here}


Regarding eating pleasure, the choice was made by the authors to not include any liking question in the present study to focus the participants on the oral sensations experienced when eating a food, and not on the affective component of food consumption. However, the link between oral comfort and food liking deserves more research as it was outlined at some occasions in the focus groups.

Regarding the run of focus group, the choice was made to have poor and good oral health volunteers in each group to increase variability of verbatims inside focus groups. This choice is questionable as elderly people with poor oral health could have been embarrassed talking about their own oral impairments in front of others. However, very few volunteers have discussed about their own oral health, only two women said having a denture and encountering problems to masticate food, those two women took part of the same focus group. None of the good oral health volunteers talked about their good oral health, which reduced the potential embarrassment felt by the other volunteers.

Regarding the "oral comfort" questionnaire itself, the choice was made to make it start with a general question on the evaluation or oral comfort when eating a food. Then, several questions decline the concept of oral comfort in four different dimensions. Therefore, there is a risk of halo effect which could induce the volunteers to rate the products as comfortable in the different dimensions if the answer of the general question of oral comfort was "comfortable" (Atkinson, Aitkinson \& Hilgard, 1983). However, and according to the correlation table (table X), the "comfort" question is only correlated to three of the texture descriptor and not correlated to any of the taste intensity questions. Therefore, the authors of the present study excluded the hypothesis of a halo effect.

Regarding product assortment, the products assessed in the present study displayed quite different texture properties. It would be interesting however to check questionnaire reliability 
and discrimination with products more alike such as different recipes for a given product. Indeed, it has been shown that consistency of products belonging to the same category of foods (jelly and custard) is positively correlated to the oral residence time and thus to the sensed difficulty of swallowing (J. Chen \& Lolivret, 2011). Furthermore, as many authors highlighted a decrease of fruit and vegetable intake with oral disorders (De Marchi et al., 2011; Akpata, Otoh, Enwonwu, Adeleke, \& Joshipura, 2011; Brodeur, Laurin, Vallee, \& Lachapelle, 1993), it will be worse to assess "oral comfort" in this product category.

\section{CONCLUSION}

As a conclusion, the present study aimed at exploring the concept of "oral comfort" when eating a food in the elderly population through the running of focus groups and the development and validation of a questionnaire that evaluates the oral comfort when eating a food. As a result, the present study attempts to describe the oral sensations perceived by older adults when eating a food, taking into account the different dimensions that underlined the concept of "oral comfort". The concept of oral comfort perception during food consumption in the elderly population was defined as a multidimensional concept: When eating, oral comfort mainly depends on easiness to chew, to humidify and to swallow as well as on texture softness. Oral pain sensations that occur when eating decrease oral comfort. Beyond these first dimensions, oral comfort also tends to be lower for dry and little melting textures, as well as for low taste intensity foods. In line with this definition, we developed a repeatable and discriminable questionnaire suitable for elderly respondents to assess oral comfort. It is a very helpful tool that aims at evaluating the food comfortability in order to understand better the elderly people's expectations in terms of food oral perception. This questionnaire might be used by those who are willing to design food products tailored to the elderly population. However, further work is needed to explore the relationship between oral health, oral comfort and food intake in the elderly. Furthermore, it 
would be interesting to consider the impact of age-related impairment on the perception of foods which display smaller sensory difference than the ones in the present experiment.

\section{Ethical Statements}

The authors declare that they do not have any conflicts of interest. The experimental protocol was approved by the French Ethics Committee for Research (CPP Est III, Nancy, \#15.04.04, ANSM \#2015-A00279-40). In accordance with ethical standards, all participants received written and oral information on the study before signing a consent form.

\section{Acknowledgements}

This study is part of AlimaSSenS [ANR-14-CE20-0003-01] funded by the French National Research Agency. This work was also supported by grants from the Regional Council of Burgundy France and the European Funding for Regional Economical Development (FEDER). The authors thank Laura Halupka (Cerelab $\left.{ }^{\circledR}\right)$, and Marine Michel (Terrena Innovation) for the work they did on the recipes and their advice on the chosen products; Françoise Durey (ChemoSens Platform) and Claire Follot for their technical support; Caroline Peltier (ChemoSens Platform) for her help and advice on the FLASH table analysis.

\section{References}

Akpata, E., Otoh, E., Enwonwu, C., Adeleke, O., \& Joshipura, K. (2011). Tooth loss, chewing habits, and food choices among older Nigerians in Plateau State: a preliminary study. Community Dent Oral Epidemiol, 39(5), 409-415.

Britton, D. (2016). The Impact of Aging and Progressive Neurological Disease on Swallowing: A Concise Overview. Journal of Texture Studies, 47(4), 257-265. 
Brodeur, J. M., Laurin, D., Vallee, R., \& Lachapelle, D. (1993). Nutrient intake and gastrointestinal disorders related to masticatory performance in the edentulous elderly. $\mathrm{J}$ Prosthet Dent, 70(5), 468-473.

Chen, C. C.-H., Schilling, L. S., \& Lyder, C. H. (2001). A concept analysis of malnutrition in the elderly. Journal of advanced nursing.

Chen, J., \& Lolivret, L. (2011). The determining role of bolus rheology in triggering a swallowing. Food Hydrocolloids, 25(3), 325-332.

de Castro, J. M., \& de Castro, E. S. (1989). Spontaneous meal patterns of humans: influence of the presence of other people. American Journal of Clinical Nutrition, 50(2), 237-347.

De Marchi, R. J., Hugo, F. N., Padilha, D. M., Hilgert, J. B., Machado, D. B., Durgante, P. C., et al. (2011). Edentulism, use of dentures and consumption of fruit and vegetables in south Brazilian community-dwelling elderly. J Oral Rehabil, 38(7), 533-540.

Dijksterhuis, G., Luyten, H., de Wijk, R., \& Mojet, J. (2007). A new sensory vocabulary for crisp and crunchy dry model foods. Food Quality and Preference, 18(1), 37-50.

Ekberg, O., \& Feinberg, M. J. (1991). Altered Swallowing Function in Elderly Patients Without Dysphagia: Radiologic Findings in 56 Cases. American Journal of Roentgenology, 156(6), 1181-1184.

Folstein, M. F., Folstein, S. E., \& McHugh, P. R. (1975). "Mini-mental state". A practical method for grading the cognitive state of patients for the clinician. J Psychiatr Res, 12(3), 189198.

Gupta, A., Epstein, J. B., \& Sroussi, H. (2006). Hyposalivation in elderly patients. J Can Dent Assoc, 72(9), 841-846. 
Iwasaki, M., Yoshihara, A., Ito, K., Sato, M., Minagawa, K., Muramatsu, K., et al. (2016). Hyposalivation and dietary nutrient intake among community-based older Japanese. Geriatr Gerontol Int, 16(4), 500-507.

Keller, H. H. (1993). malnutrition in Institutionalized elderly: How and Why? Journal of the American Geriatrics Society, 41, 1212-1218.

Kim, J. M., Stewart, R., Prince, M., Kim, S. W., Yang, S. J., Shin, I. S., et al. (2007). Dental health, nutritional status and recent-onset dementia in a Korean community population. Int $\mathrm{J}$ Geriatr Psychiatry, 22(9), 850-855.

Kimura, Y., Ogawa, H., Yoshihara, A., Yamaga, T., Takiguchi, T., Wada, T., et al. (2013). Evaluation of chewing ability and its relationship with activities of daily living, depression, cognitive status and food intake in the community-dwelling elderly. Geriatr Gerontol Int, 13(3), 718-725.

Leake, J. L., Hawkins, R., \& Locker, D. (1994). Social and functional impact of reduced posterior dental units in older adults. J Oral Rehabil, 21(1), 1-10.

Marcenes, W., Steele, J. G., Sheiham, A., \& Walls, A. W. (2003). The relationship between dental status, food selection, nutrient intake, nutritional status, and body mass index in older people. Cadernos de Saude Publica, 19(3), 809-816.

Methven, L., Jiménez-Pranteda, M. L., \& Lawlor, J. B. (2016). Sensory and consumer science methods used with older adults: A review of current methods and recommendations for the future. Food Quality and Preference, 48, 333-344. 
Mioche, L., Bourdiol, P., Monier, S., \& Martin, J. F. (2002). The relationship between chewing activity and food bolus properties obtained from different meat textures. Food Quality and Preference, 13(7-8), 583-588.

Mioche, L., Bourdiol, P., \& Peyron, M. A. (2004). Influence of age on mastication: effects on eating behaviour. Nutrition Research Reviews, 17(1), 43-54.

Muñoz-González, C., Vandenberghe-Descamps, M., Feron, G., Canon, F., Labouré, H., \& Sulmont-Rossé, C. (submitted). Does salivary hypofunction affect food consumption in the elderlies? A Systematic Literature Review.

Porcherot, C., \& Schlich, P. (2000). FLASH table and canonical mapping of potato varieties. Food Quality and Preference, 11(1-2), 163-165.

Savoca, M. R., Arcury, T. A., Leng, X., Chen, H., Bell, R. A., Anderson, A. M., et al. (2010). Severe tooth loss in older adults as a key indicator of compromised dietary quality. Public Health Nutr, 13(4), 466-474.

Schlich, P. (1998). What are the sensory differences among coffees? Multi-panel analysis of variance and FLASH analysis. Food Quality and Preference, 9(3), 103-106.

Tada, A., \& Miura, H. (2014). Systematic review of the association of mastication with food and nutrient intake in the independent elderly. Arch Gerontol Geriatr, 59(3), 497-505.

Van Lancker, A., Verhaeghe, S., Van Hecke, A., Vanderwee, K., Goossens, J., \& Beeckman, D. (2012). The association between malnutrition and oral health status in elderly in long-term care facilities: a systematic review. Int J Nurs Stud, 49(12), 1568-1581. 
Vandenberghe-Descamps, M., Labouré, H., Prot, A., Septier, C., Tournier, C., Feron, G., et al. (2016). Salivary Flow Decreases in Healthy Elderly People Independently of Dental Status and Drug Intake. Journal of Texture Studies, 47(4), 353-360.

Vandenberghe-Descamps, M., Sulmont-Rossé, C., Septier, C., Feron, G., \& Laboure, H. (Submitted). Using food comfortability to compare food's sensory characteristics expectations of elderly people with or without oral health problems. Journal of Texture Studies.

Vissink. (1996). Aging and saliva: A review of the literature. Special Care in Dentistry, 16(3).

Wansink, B., Cheney, M., \& Chan, N. (2003). Exploring comfort food preferences across age and gender1. Physiology \& Behavior, 79(4-5), 739-747.

Witter, D. J., De Haan, A. F. J., Käyser, A. F., \& Van Rossum, G. M. J. M. (1994). A 6-year follow-up study of oral function in shortened dental arches. Part II: Craniomandibular dysfunction and oral comfort. Journal of Oral Rehabilitation, 21, 353-366. 
Table 1: List of the selected foods for the focus group

\begin{tabular}{llll}
\hline Started course & Main course & Cheese course & Dessert course \\
\hline Sliced tomato & Steam cooked zucchini & Baguette & Apple \\
Red beetroot & Rice & White bread & Syrup peer \\
Minced carrots & Split pees puree & Rye bread & Banana \\
Curly endive & Green beans & Crispbread & White grapes \\
Crumbed tuna fish & Ground beef & Vanilla jelly & Waffle \\
Dry sausage & Turkey escalope & Comté cheese & Almond biscuit \\
White ham & Boiled beef & Vanilla cream & Madeleine \\
Raw ham & Roast beef & Light spread cheese & Shortbread biscuit \\
\hline
\end{tabular}


Table 2: List of word categories resulting from the focus groups

\begin{tabular}{ccc}
\hline Categories & Occurrence frequencies (\%) & Number of different words \\
\hline Body sensations & 3 & 11 \\
Bolus formation & $\mathbf{3 0}$ & $\mathbf{2 3}$ \\
Cooking & 5 & 11 \\
Eating & 1 & 4 \\
Flavor perception & $\mathbf{1 8}$ & $\mathbf{2 1}$ \\
Meal environment & 0,2 & 2 \\
Odor & 1 & 1 \\
\hline Mouth anatomy & 0,1 & 1 \\
Oral pain sensations & 1 & 7 \\
Texture perception & $\mathbf{3 9}$ & $\mathbf{5 2}$ \\
Visual & 2 & 6 \\
\hline TOTAL & $100 \%$ & 139 \\
\hline
\end{tabular}


Table 3: description of the tasted products

\begin{tabular}{|c|c|c|c|c|}
\hline & $\begin{array}{l}\text { Name of the } \\
\text { product }\end{array}$ & Description & Illustration & portion size \\
\hline \multirow{6}{*}{ 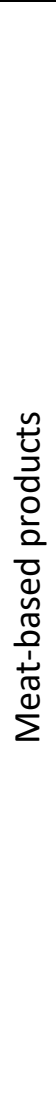 } & Beef cheek & $\begin{array}{l}\text { Slow cooked Beef cheek } \\
\text { braised in a sauce with } \\
\text { carrots }\end{array}$ & & 2 pieces \\
\hline & Beefsteak & Beefsteak & & $1 / 2$ of a beefsteak \\
\hline & Ground beef & Ground beef & & $1 / 2$ of a beefsteak \\
\hline & Chicken meatballs & $\begin{array}{l}\text { Ground chicken } \\
\text { reconstituted in meatballs } \\
\text { shape }\end{array}$ & & 3 meatballs \\
\hline & $\begin{array}{l}\text { Chicken } \\
\text { aiguillette }\end{array}$ & $\begin{array}{l}\text { Chicken breast sliced into } \\
\text { an aiguillette shape }\end{array}$ & & 3 aiguillettes \\
\hline & $\begin{array}{l}\text { Ground chicken } \\
\text { reconstituted }\end{array}$ & $\begin{array}{l}\text { Ground chicken breast } \\
\text { reconstituted in an } \\
\text { aiguillette shape }\end{array}$ & & 2 aiguillettes \\
\hline \multirow{6}{*}{ 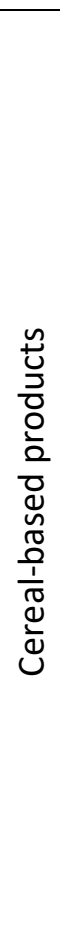 } & Crispbread & $\begin{array}{l}\text { Flat and dry bread made of } \\
\text { white bread dried and } \\
\text { double cooked }\end{array}$ & & 1 slice \\
\hline & Financier & $\begin{array}{l}\text { Small cake cooked in a } \\
\text { mold, made of almond } \\
\text { powder, flour, sugar, } \\
\text { butter and eggs. }\end{array}$ & & 1 financier \\
\hline & Madeleine & $\begin{array}{l}\text { Small cake cooked in a } \\
\text { mold, made of flour, eggs, } \\
\text { sugar and butter }\end{array}$ & & 1 madeleine \\
\hline & Sponge cake & $\begin{array}{l}\text { Cake with a well-aerated } \\
\text { crumb cooked in a cake } \\
\text { mold, made of flour, sugar } \\
\text { and eggs, }\end{array}$ & & $1 / 16$ of the cake \\
\hline & Milk roll & $\begin{array}{l}\text { Melting bread made of } \\
\text { flour, milk, egg, sugar and } \\
\text { butter }\end{array}$ & & $1 / 2$ of the bread \\
\hline & $\begin{array}{l}\text { Protein enriched } \\
\text { milk roll }\end{array}$ & $\begin{array}{l}\text { Milk roll enriched with } \\
\text { vegetable protein }\end{array}$ & & $1 / 2$ of the bread \\
\hline
\end{tabular}



Table 3: Flash table for the meat-based products

\begin{tabular}{|c|c|c|c|c|c|c|c|c|c|}
\hline & F-Prod & $P(F)$ & GMEAN & $\begin{array}{c}\text { Chicken } \\
\text { balls }\end{array}$ & $\begin{array}{c}\text { Beef } \\
\text { cheek }\end{array}$ & $\begin{array}{l}\text { Chicken } \\
\text { aiguillette }\end{array}$ & $\begin{array}{c}\text { Recon. } \\
\text { Chicken } \\
\text { aiguillette }\end{array}$ & $\begin{array}{c}\text { Ground } \\
\text { beef }\end{array}$ & $\begin{array}{l}\text { Plain } \\
\text { beef }\end{array}$ \\
\hline \multicolumn{10}{|c|}{ General question } \\
\hline comfort & 14.46 & $* * *$ & 70 & $80+$ & $80+$ & $78+$ & 67 & 61- & 54- \\
\hline \multicolumn{10}{|c|}{ Food oral processing } \\
\hline incisor & 42.01 & $* * *$ & 25 & 13- & $16-$ & $14-$ & $17-$ & $30+$ & $55+$ \\
\hline molar & 35.26 & $* * *$ & 17 & 8- & $11-$ & 8- & $11-$ & $22+$ & $41+$ \\
\hline masticate & 37.45 & $* * *$ & 18 & 9- & $10-$ & 9- & 14- & $27+$ & $41+$ \\
\hline humidify & 8.45 & $* * *$ & 24 & $17-$ & 15- & 21 & 26 & $28+$ & $32+$ \\
\hline swallow & 20.34 & $* * *$ & 19 & 11- & 10- & $12-$ & 20 & $23+$ & $33+$ \\
\hline time & 24.09 & $* * *$ & 3 & 19- & 18- & 27 & 28 & $36+$ & $47+$ \\
\hline \multicolumn{10}{|c|}{ Pain encountered while eating } \\
\hline muscle & 5.89 & $* * *$ & 2 & 1 & 1 & $0-$ & 1 & 1 & $7+$ \\
\hline articular & 10.54 & $* * *$ & 3 & $0-$ & 1 & 1 & 1 & 3 & $11+$ \\
\hline dental & 4.06 & $* *$ & 2 & 1 & 1 & 0 & 2 & 0 & $5+$ \\
\hline gum & 2.28 & $*$ & 1 & 0 & 1 & 0 & 1 & 1 & $4+$ \\
\hline \multicolumn{10}{|c|}{ Texture (intensity) } \\
\hline sticky & 2.18 & & 15 & 15 & 18 & 13 & $20+$ & 17 & 9- \\
\hline stringy & 28.14 & $* * *$ & 19 & 3- & $41+$ & $11-$ & $12-$ & $12-$ & $33+$ \\
\hline greasy & 12.12 & $* * *$ & 20 & $28+$ & $31+$ & 7- & 17 & $26+$ & 8- \\
\hline dry & 13.51 & $* * *$ & 23 & 18 & 4- & $28+$ & $36+$ & $30+$ & $17-$ \\
\hline doughy & 12.94 & $* * *$ & 21 & $28+$ & $12-$ & 17 & $33+$ & $25+$ & 8- \\
\hline melting & 24.31 & $* * *$ & 27 & 29 & $55+$ & 28 & 19- & $15-$ & 15- \\
\hline firm & 29.54 & $* * *$ & 24 & 7- & 8- & 24 & 20 & 28 & $53+$ \\
\hline hard & 25.11 & $* * *$ & 11 & $0-$ & 1- & 6- & 6- & $17+$ & $36+$ \\
\hline \multicolumn{10}{|c|}{ Flavor (intensity) } \\
\hline $\begin{array}{l}\text { Taste } \\
\text { intense }\end{array}$ & 8.77 & $* * *$ & 29 & 25 & $38+$ & 32 & 22- & $17-$ & $40+$ \\
\hline salty & 5.69 & $* * *$ & 18 & $22+$ & 16 & $22+$ & $23+$ & 8- & 17 \\
\hline
\end{tabular}

The FLASH table gives the mean of every item of the questionnaire for each product, the results were transformed on a score varying from 0 to 100. The scales range from "very uncomfortable" to "very comfortable" for the general question; from "impossible" to "very easy" for the food oral procession dimension, from "not at all" to "a lot" for the last three dimensions (pain encountered while eating, texture intensity and flavor intensity). The sign " + " indicates that the product has a mean significantly higher than the general mean of the products for the related item. The sign "-" indicates that the product has a mean significantly lower than the general mean of the products for the related item.

The columns F-prod and $P(F)$ correspond to the product effect $\left({ }^{*} P<0.05 ;{ }^{*} P<0.01 ;{ }^{* * *} P<0.001\right)$. The column GMAEN corresponds to the mean of every item all products taken together. 
Table 4: Flash table for the cereal-based products

\begin{tabular}{|c|c|c|c|c|c|c|c|c|c|}
\hline & F-Prod & $P(F)$ & GMEAN & $\begin{array}{c}\text { Sponge } \\
\text { cake }\end{array}$ & Madeleine & Financier & Milk roll & $\begin{array}{l}\text { Protein } \\
\text { enriched } \\
\text { milk roll }\end{array}$ & Crispbread \\
\hline \multicolumn{10}{|c|}{ General question } \\
\hline comfort & 5.95 & $* * *$ & 76 & $85+$ & $81+$ & 78 & 75 & 70- & 69- \\
\hline \multicolumn{10}{|c|}{ Food oral processing } \\
\hline incisor & 10.85 & $* * *$ & 12 & 7- & 6- & 11 & 13 & $17+$ & $20+$ \\
\hline molar & 13.49 & $* * *$ & 11 & 7- & 7- & 8- & 10 & $16+$ & $18+$ \\
\hline masticate & 11.26 & $* * *$ & 10 & 6- & 5- & 8 & 10 & $16+$ & $16+$ \\
\hline humidify & 9.02 & $* * *$ & 20 & 18 & 15- & 14- & 20 & $28+$ & $25+$ \\
\hline swallow & 8.65 & $* * *$ & 14 & 10- & 11 & 9- & 14 & $22+$ & $18+$ \\
\hline time & 13.85 & $* * *$ & 27 & 23- & 18- & 24- & 26 & $38+$ & $32+$ \\
\hline \multicolumn{10}{|c|}{ Pain encountered while eating } \\
\hline burn & 2.01 & & 1 & 0 & 1 & $3+$ & 1 & $3+$ & 0 \\
\hline dental & 3.99 & $* *$ & 0 & 0 & 0 & 0 & 0 & 0 & $3+$ \\
\hline gum & 6.16 & $* * *$ & 1 & 0 & 1 & 0 & 0 & 1 & $5+$ \\
\hline \multicolumn{10}{|c|}{ Texture (intensity) } \\
\hline sticky & 7.15 & $* * *$ & 23 & 20 & $28+$ & 26 & 26 & 26 & 10- \\
\hline stringy & 2.83 & * & 2 & 1 & 1 & 1 & $4+$ & $5+$ & 2 \\
\hline greasy & 26.64 & $* * *$ & 18 & 9- & $25+$ & $36+$ & 20 & 17 & 4- \\
\hline dry & 49.89 & $* * *$ & 25 & 21 & 13- & 9- & 13- & $29+$ & $63+$ \\
\hline doughy & 25.90 & $* * *$ & 26 & $20-$ & $31+$ & $32+$ & $34+$ & $35+$ & 6- \\
\hline melting & 17.30 & $* * *$ & 29 & $37+$ & $38+$ & $40+$ & 31 & $12-$ & 16- \\
\hline firm & 33.61 & $* * *$ & 23 & 9- & $13-$ & 23 & 7- & $33+$ & $50+$ \\
\hline hard & 52.46 & $* * *$ & 10 & 1- & 2- & 4- & $0-$ & 9 & $41+$ \\
\hline \multicolumn{10}{|c|}{ Flavor (intensity) } \\
\hline $\begin{array}{l}\text { Taste } \\
\text { intense }\end{array}$ & 15.38 & $* * *$ & 30 & 29 & $42+$ & $40+$ & 31 & 29 & $12-$ \\
\hline salty & 15.77 & $* * *$ & 10 & 4- & 6- & 6- & 8 & $12+$ & $21+$ \\
\hline sugary & 34.80 & $* * *$ & 39 & $44+$ & $45+$ & $51+$ & 42 & 37 & $14-$ \\
\hline acidic & 2.89 & $*$ & 3 & 2 & 2 & 3 & 5 & $6+$ & 1- \\
\hline bitter & 3.23 & $* *$ & 4 & 2 & 5 & 3 & 6 & $9+$ & 1- \\
\hline
\end{tabular}

The FLASH table gives the mean of every item of the questionnaire for each product, the results were transformed on a score varying from 0 to 100. The scales range from "very uncomfortable" to "very comfortable" for the general question; from "impossible" to "very easy" for the food oral procession dimension, from "not at all" to "a lot" for the last three dimensions (pain encountered while eating, texture intensity and flavor intensity). The sign " + " indicates that the product has a mean significantly higher than the general mean of the products for the related item. The sign "-" indicates that the product has a mean significantly lower than the general mean of the products for the related item.

The columns F-prod and $\mathrm{P}(\mathrm{F})$ correspond to the product effect ( ${ }^{*} \mathrm{P}<0.05 ;{ }^{* *} \mathrm{P}<0.01$; $\left.{ }^{* *} \mathrm{P}<0.001\right)$. The column GMAEN corresponds to the mean of every item all products taken together. 